REVIEW

\title{
Drug repositioning for COVID-19
}

\section{Reposicionamiento de medicamentos para COVID-19}

\author{
Vicente Benavides-Cordoba \\ vicente.benavides@correounivalle.edu.co \\ Universidad del Valle, Facultad de Salud, Escuela de Ciencias Básicas. Cali, Colombia
}

\section{Abstract}

Drug repositioning is a strategy that identifies new uses of approved drugs, to treat conditions different from their original purpose. With the advance of COVID-19 and the declaration of a pandemic; It has become the closest alternative to slow the advance of the virus. Antimalarial, antiviral drugs, antibiotics, glucocorticoids, monoclonal antibodies, among others, are being studied; his findings, although preliminary, could establish a starting point in the search for a solution. In this article, we present a selection of drugs, of different classes and with potential activity to combat COVID-19, whose trials are ongoing; and as proofs of concept, double blind, event-driven add-on, would allow proposing research that generates results in less time and preserving the quality criteria for drug development and approval by regulatory agencies.

\section{Resumen}

El drug repositioning, es una estrategia que identifica nuevos usos de medicamentos aprobados, para tratar condiciones diferentes a las de su propósito original. Con el avance del COVID-19 y la declaración de pandemia; se ha convertido en la alternativa más cercana para frenar el avance del virus. Fármacos antimalariales, antivirales, antibióticos, glucocorticoides, anticuerpos monoclonales entre otros están siendo estudiados; sus hallazgos, aunque preliminares, podrían establecer un punto de partida en la búsqueda de la solución. En este artículo, se presenta una selección de fármacos, de distinta clase y con potencial actividad para combatir al COVID-19, cuyos ensayos se encuentran en curso; y como las prueba de concepto, double blind, add-on event-driven, permitirían proponer investigaciones que generen resultados en menor tiempo y conservando los criterios de calidad para el desarrollo de medicamentos y su aprobación por las agencias reguladoras. 
Conflict of Interest:

None

\section{Acknowledgments}

Thanks to Professor Mauricio Palacios Gómez of the Escuela de Ciencias Básicas - Universidad del Valle.

\section{Corresponding author:}

Vicente Benavides. Universidad del Valle, Facultad de Salud, Escuela de Ciencias Básicas. Cali, Colombia e-mail: vicente. benavides@correounivalle.edu.co

\section{Remark}

\section{Why was this study conducted?}

In pandemic of COVID-19, researchers around the world have focused their efforts on finding the solution; drug repositioning is currently the closest response option. The review describes the repositioning treatments that aim to slow down the progression of the virus, and what are the alternatives to propose studies that balance the quality / time relationship.

\section{What were the most relevant results of the study?}

Research centers, universities and the pharmaceutical industry have mobilized to propose approved drugs with different indications, which could have an effect on SARS-CoV-2; new trials are registered every day, and countries such as China and the United States lead the number of studies proposed. It is necessary for countries and regulatory agencies to establish flexible guidelines that allow research to be facilitated without compromising quality; all the actors involved must have a proactive and updated participation. Proofs of concept, double blind, add-on event-driven, offer the necessary characteristics to obtain reliable, reproducible results in less time

\section{What do these results contribute?}

Beyond delving into the drugs that are currently being proposed for a second use; This review describes the global context of repositioning for COVID-19, and what are the proposed strategies that would allow researchers to conduct high-quality scientific trials that generate reliable and applicable results in the short and medium term.

\section{Introduction}

The new disease caused by the coronavirus (COVID-19) was reported in the city of Wuhan, Hubei province in China, and has spread rapidly around the world. Infected patients have been reported in 210 countries. This disease was declared as pandemic by the World Health Organization on March 12th (WHO) ${ }^{1}$.

SARS-CoV-2 is a positive single-stranded RNA beta-coronavirus. Like SARS and MERS, the genome encodes non-structural proteins such as chymotrypsin type 3 protease, papain-like protease, helicase, and RNA-dependent RNA polymerase; and structural proteins such as spike glycoprotein and accessory proteins ${ }^{2}$. So far, there are no vaccines that had been approved. However, just a few weeks after the first reports of the disease, several laboratories began investigating for a vaccine that immunizes against this virus, and approximately 37 research laboratories and academic centres are currently doing so ${ }^{3}$. Vaccine development already has a starting point from the knowledge gained from the SARS-CoV and MERS epidemics and the selection of antigens based on them. However, it would take several months for a vaccine to have a consistent safety profile across populations and to mimic the immune response ${ }^{4}$.

Another option would be to develop new molecules that allow treating the disease according to its stage; however, this process could be even slower. Furthermore, de novo drug development takes place in an environment where preclinical research findings may not be replicated ${ }^{5}$. Likewise, when researching new molecules in humans, it is necessary to ask several questions that could improve the designs, and avoid some failures, such as, for example, did the drug hit the target?, did the medication change the target?, what was the dose response?, and what are the characteristics of the study patients?. To answer these questions, you need financial resources and time, which in many occasions must be abundant ${ }^{6}$. 
According to the advances in technology and knowledge of human disease, the transfer of these benefits in advance has great expectations, and moreover, the challenges of the pharmaceutical industry are great and exhausting ${ }^{7}$. The costs and time required for the development of a medicine have made working with the industry less attractive to researchers ${ }^{8}$, which is accentuated by the global economic crisis secondary to the pandemic.

Due to this, the strategy that could offer results in less time, with better levels of safety and at a lower cost is known as "Drug Repurposing". This strategy consists of identifying new uses of approved drugs different from the original therapeutic indication. ${ }^{9}$. This strategy differs from "Off Label" use in that it requires research and development to gain regulatory agency approval ${ }^{10}$. It has several advantages; first, the risk of toxicity failure is low because the drug is safe enough and has been tested in preclinical and early human studies. Second, the time is reduced since preclinical and safety studies have already been carried out, and third, the necessary resources are less ${ }^{11}$. These advantages can generate a quick return on investment (300 million dollars in repositioning against 2-3 trillion dollars in the study of a new molecule) and in case of failure there is less loss ${ }^{12}$. About 3422 medicines that have been described in human clinical trials are in the marketing phase around the world, thus, the possibility of selection is wide ${ }^{13}$.

Three actors have been identified in the field of repurposing: the academy, the research institutes and, of course, the pharmaceutical industry, each with its own characteristics. In academia and research institutes, there is less need for economic or commercial success, but they depend on securing resources from the state or other funder. Furthermore, the pharmaceutical industry has the complete platform to do the trials, but they are not always motivated because many countries do not recognize second-use patents ${ }^{14}$.

Among the diseases in which researchers are using repositioning are cancer (thalidomide, metformin, chlorpromazine, digoxin, doxycycline) ${ }^{15-17}$, neurodegenerative diseases such as Parkinson's (ambroxol, amantadine) ${ }^{18}$, viral and infectious diseases (azithromycin, mycophenolic acid) ${ }^{19,20}$, asthma and allergies (ruxolitinib, imatinib, metformin) ${ }^{21}$, neuropathic pain (gabapentin, amitriptyline) ${ }^{22}$, kidney disease (levosimendan, allopurinol) ${ }^{23}$ and cardiovascular-pulmonary disease (tadalafil, fasudil) ${ }^{24-26}$.

The best examples of Drug Repurposing are in the cardiovascular system, from the use of aspirin as a platelet antiplatelet ${ }^{27}$ to the approval of Sildenafil, a drug previously used for erectile dysfunction that is now the first-line treatment in pulmonary hypertension. ${ }^{28,29}$.

\section{Therapeutic alternatives in the management of SARS-CoV-2 infection}

Since the first reports of coronavirus's infections began to be known in late 2019 in China, studies have been started with drugs approved for other diseases. To date, there are 908 studies registered at www.clinicaltrials.gov, of which 560 are intervention studies that include clinical trials of repositioning in Covid-19, mostly from China. ${ }^{30}$.

Chloroquine, which was initially approved for the treatment of malaria ${ }^{31}$, and which has been studied in approximately 400 diseases (with the first trial being carried out in 1946) ${ }^{32}$, was evaluated for the treatment of SARS-CoV infection in $2003{ }^{33}$ and now in the SARS$\mathrm{CoV}-2$ pandemic ${ }^{34}$. Hydroxychloroquine, a chloroquine analog, is a medicine widely used in the treatment of systemic autoimmune diseases ${ }^{35}$, being currently the most studied drug for treating COVID-19. Hydroxychloroquine is metabolized in the liver and is eliminated via the kidneys after 30 to 50 days. It is a 4 -aminoquinolone with immunosuppressive, anti-autophagic and antimalarial properties. Although its mechanism of action is unknown, it can suppress 
Figure 1. Medicamentos estudiados en las distintas etapas de severidad de COVID-19 Severity Drugs

Interferon Alpha-1b

Hydroxychloroquine

Prophylaxis in healthcare workers

Emtricitabine/Tenofovir + Disoproxil

\section{Evaluation}

Related Symptoms

Adverse Drug Reactions

RT-PCR Positive during follow-up

Time to first clinical event

Hospitalization / ICU requirement

Measurement of drugs in plasma

Related Symptoms

Adverse Drug Reactions

RT-PCR Positive during follow-up

Difference in incidence of infection

Hospitalization / ICU requirement

Measurement of drugs in plasma

Lopinavir/Ritonavir

Umifenovir

Mortality

Colchicine

Azithromycin + Hydroxychloroquine

Hydroxychloroquine

Anluohuaxian

Outpatients diagnosed with COVID19

Thalidomide

Deferoxamine

Ciclesonide

Tranexamic Acid

Peginterferon Lambda- $1^{\underline{a}}$

Chloroquine

Levamisol + Budesonide + Formoterol

Hydroxychloroquine

Hydroxychloroquine + Azithromycin

Camostat Mesilate

Piclinedoson

Inpatients diagnosed with COVID19

Lopinavir/Ritonavir

Ibuprofen

Anakinra + Tocilizumab

Famotidine
NIMV or IMV requirement

Need for hospitalization / ICU

$\mathrm{PaO} 2$

$\mathrm{C}$ reactive protein

Lymphocyte count

Time to clinical recovery *

Time to negative RT-PCR

Viral load SARS-CoV2

Adverse Drug Reactions
Mortality

NIMV or IMV requirement

Days in hospitalization

Hospitalization / ICU requirement

$\mathrm{PaO} 2$

$\mathrm{C}$ reactive protein

Lymphocyte count

Time to clinical recovery *

Time to negative RT-PCR

Viral load SARS-CoV2

Adverse Drug Reactions
Xiyanping

Lopinavir/Ritonavir + alpha-interferon

Carrimycin

Ritonavir + Oseltamivir

Favipiravir + Hydroxychloroquine

Pirfenidone

Bromhexine + Umifenovir + Interferon $\alpha 2 b$

Hydroxychloroquine + Azithromycin

Tocilizumab

Danoprevir/Ritonavir

Bevacizumab

Escin

Fingolimod

Baricitanib

Ganovo + Ritonavir + Interferon

Colchicine

IFX-1

Darunavir + Cobicistat

Maviriblumab

Tetrandine

Defibrotide

Symbicort

Tofacitinib
WHO Ordinal Scale**

Mortality

ICU requirement

NIMV or IMV requirement

Pneumonia severity index***

Time to clinical recovery *

Time to negative RT-PCR

$\mathrm{C}$ reactive protein

Lymphocyte count

D Dimer

Changes in $\mathrm{Pa} / \mathrm{FiO} 2$

Changes in hemoglobin

Kidney and liver function

Interleukin 6 levels

$\mathrm{PaO} 2$

Changes in SOFA score

Radiological response

Viral load SARS-CoV2

Hyperinflammation score

Adverse Drug Reactions 


\begin{tabular}{lll}
\hline Severity & Drugs & Evaluation \\
& & WHO Ordinal Scale $* *$ \\
& Mopinavir/Ritonavir + Rivabirine & IMV or NIMV days \\
& Hydroxychloroquine & Time until oxygen weaning \\
& Metilprednisolon & Pneumonia severity index** \\
& Eculizumab & Time to clinical recovery \\
& Ruxolitinib & Time to SARS-CoV2 undetectable RNA \\
SARS & Tocilizumab & Hospital discharge \\
& Bevacizumab & Hospitalization /ICU days \\
& Dexamethasone & ECMO Requirement \\
& Aviptadil & PaO2/FiO2 \\
& Sargramostim & D Dimer \\
& Remdesivir & Lymphocyte count \\
& Thalidomide & Changes in C3 / C4 complement factors \\
& Ruxolitinib & C reactive protein \\
& DAS-181 & Kidney and liver function \\
& & Time to negative RT-PCR \\
& & Adverse Drug Reactions \\
\hline
\end{tabular}

SARS: Severe acute respiratory syndrome, ICU: Intensive Care Unit, PaO2: Oxygen blood pressure, IMV: Invasive Mechanical Ventilation, NIMV: Non-invasive Mechanical Ventilation, ECMO: Extracorporeal membrane oxygenation, RNA: Ribonucleic acid

${ }^{\star}$ Clinical recovery: Relief of fever, elimination of cough, oxygen saturation at normal levels maintained for 72 hours.

${ }^{* *} 0$ : No clinical or virological evidence of infection, 1 : No limitation of activities, 2: Limitation of activities, 3: No supplemental oxygen, 4: Oxygen by cannula or mask, 5: Non-invasive ventilation or high flow oxygen, 6: Mechanical ventilation, 7: Ventilation + additional organ support, 8: Death

$* * \star \mathrm{SpO} 2 \leq 93 \%$ o $\mathrm{PaO} 2 / \mathrm{FiO} 2 \leq 300$, respiratory rate $\geq 30 / \mathrm{min}$, requirement for oxygen support or ventilatory support

immune function by interfering with antigen processing and presentation ${ }^{36,37}$. It is a medicine with a higher risk / benefit than chloroquine and allows higher doses to be used. In COVID 19, 133 clinical trials are registered, taking different degrees of severity, ranging from prophylactic use in the general population and in health workers ${ }^{38}$ to patients with severe acute respiratory syndrome (SARS). It is believed that, as happened with SARS-CoV, it could reduce the viral load of patients in pre and post infection stages, in addition to reducing the expression of CD154 in T cells ${ }^{39}$.

The results obtained so far are controversial, since on the one hand it has been reported that treatment with hydroxychloroquine did not generate additional effects to standard treatment and instead increased the risk of ventilatory support ${ }^{40}$, and on the other, French researchers documented that the addition of azithromycin to hydroxychloroquine treatment can generate synergistic effects by improving the elimination of the virus. It is necessary to clarify that the previously described are preliminary studies and that they require large sample sizes to generate a definitive conclusion ${ }^{41}$. This mixture is being studied for treating patients with and without complications (Table 1).

Antivirals are other group of drugs being tested to combat the pandemic. In Wuhan, more than $85 \%$ of patients received medications such as Oseltamivir, Remdesivir, Ganciclovir, Lopinavir/Ritonavir and Ribavirin ${ }^{42,43}$. These antivirals have been combined with systemic corticosteroids and inhalation of interferon in the treatment of patients with severe complications ${ }^{44}$. Satisfactory results were achieved using Remdesivir, obtaining clinical improvement in $68 \%$ of patients with SARS, with a significant reduction in mortality, days of hospitalization and days of mechanical ventilation. This study was developed with patients from the United States, Japan, Italy, Austria, France, Germany, the Netherlands, Spain and Canada ${ }^{45}$, however, just as it happens with hydroxychloroquine, its effectiveness should be contrasted with more clinical trials and in more patients.

Immunotherapy has shown effectiveness in the treatment of infectious diseases; thus, the use of monoclonal antibodies constitutes a new stage in their prevention, due to its versatility and specificity. ${ }^{46,47}$. Therapy with antibodies that bind to the angiotensin 2-converting enzyme 
receptor may block the virus from entering the cell ${ }^{48,49}$. Currently there are 15 trials registered in Clinical Trials that are testing this hypothesis, using monoclonal antibodies, which are being performed only in complicated patients, none in stable patients or in prophylaxis.

Famotidine, a histamine $\mathrm{H} 2$ receptor antagonist; have shown effects on inmune system ${ }^{(50)}$ It is currently being studied and results obtained in patients in China can generate positive expectations, currently in the United States, they are in the recruitment phase; the reduction of the mortality and its low probability of adverse effects generates an attractiveness for researchers ${ }^{(51,52)}$. Glucocorticoids (Methylprednisolone and Dexamethasone) as monotherapy with discrete results ${ }^{53}$, or accompanying other medications such as thalidomide ${ }^{54}$; antiinflammatories such as colchicine ${ }^{55}$, or drugs that do not yet have a clear mechanism of action such as pirfenidone, are being studied to be repositioned in Covid-19. China and the United States lead most of the trials, however, countries such as Italy, Spain, the United Kingdom, Canada, and Denmark ${ }^{56}$ also participate in the search for a medicine that could change the course of a crisis that can only be compared to the world wars of the early twentieth century. With all the limitations, repositioning tests are an attractive strategy, providing the possibility of combinations that seek synergism ${ }^{57}$. The search for these treatments is an obligation acquired by science and public health.

\section{Research strategies to evaluate drug repositioning}

There are controversies about the maximum and minimum recommendations and the essential requirements to conduct a good clinical trial of drug repositioning. The infrastructure, the preparation of products, materials, protocols, forms of reporting, databases, statistics, monitoring and reports, as well as laboratory evaluations are often insufficient ${ }^{58}$ and their availability is reserved, a situation that is accentuated with the pandemic ${ }_{59}$, therefore, the maximum recommendations should be flexible when approving studies.

The COVID-19 Clinical Research Coalition initiative establishes flexible guidelines that allow research to be carried out. This initiative shows that the research agenda should not be controlled, but facilitated, for which 4 objectives are proposed: first, to facilitate rapid reviews by ethics committees and regulatory agencies; second, to facilitate permits for the importation of medicines and materials, as was done with the Ebola vaccine trials; third, to ensure simple data collection strategies sufficient to strengthen efficacy analyses; and fourth, to provide a reference framework for governments to share the results obtained before publishing in scientific journals ${ }^{60}$. Compliance with these objectives will allow studies to be carried out in shorter times and with enough resources to ensure quality. Thus, the Food and Drug Administration (FDA) in the United States ${ }^{61}$, and the INVIMA in Colombia, approved the use of hydroxychloroquine in hospitalized patients via fast track.

To move forward and generate fast and reliable results, it might be considered doing a proof of concept, double blind, add-on event-driven. In Add-On studies, one group receives the standard treatment, while the other group receive the drug to be tested in addition to the standard treatment. Using these studies, the comparison of relative or absolute efficacy could be obtained in short periods of time ${ }^{62}$. The FDA Recognizes Add-On designs in Cancer, Behavioural Disorders, HIV, and Heart Failure studies ${ }^{63}$. In this methodology processes are developed over time and results are produced that then turn into events that ultimately lead to additional results as the narrative unfolds. ${ }^{64}$.

Unlike most diseases, there are currently no proven treatments to treat COVID-19. Therefore, there are 183 registered studies that use placebo as a comparator of the drug to be repurposed ${ }^{65-67}$. The ethics committees are expected to be willing to meet the needs that the ethical conflict the placebo group generates, with enough updating to control the ethical aspects without preventing the execution of the projects. Probably there will be problems, one of them would be the entry of participants linked to the health system who could "sabotage" the study, taking 
the drug without belonging to the experimental group or trying another drug at the same time in the hope of avoiding a contagion or treating the illness.

\section{Conclusion}

The dissemination of these findings should be responsible, avoiding anecdotal evidence ${ }^{68}$. Differences in plasma concentrations of medicines from person to person could generate more adverse reactions, and therefore, rapid clinical trials but with high scientific quality should be carried out ${ }^{38}$. While the vaccine arrives, the repositioning of medicines will continue to be the first research strategy against this crisis that has changed the rhythm of life of humanity.

\section{References}

1. WHO. Coronavirus Disease (COVID-19) - events as they happen; 2020. Available from: https://www.who.int/ emergencies/diseases/novel-coronavirus-2019/events-as-they-happen.

2. Li G, De Clercq E. Therapeutic options for the 2019 novel coronavirus (2019-nCoV). Nat Rev Drug Discov. 2020;19(3):149-50. Doi: 10.1038/d41573-020-00016-0

3. Prompetchara E, Ketloy C, Palaga T. Immune responses in COVID-19 and potential vaccines: lessons learned from SARS and MERS epidemic. Asian Pac J Allergy Immunol. 2020;38(1):1-9. Doi: 10.12932/ap200220-0772

4. Della G, Jonsdottir, I. Lewis D. Challenges in early clinical development of adjuvanted vaccines. Vaccine. 2015;33:47-51. Doi: 10.1016/j.vaccine.2015.02.031

5. Esch EW. BA, Huh D. Organs-on-chips at the frontiers of drug discovery. Nat Rev Drug Discov. 2015;14(4):248-60. Doi: 10.1038/nrd4539

6. Lythgoe MP, Rhodes CJ, Ghataorhe P, Attard M, Wharton J, Wilkins MR. Why drugs fail in clinical trials in pulmonary arterial hypertension, and strategies to succeed in the future. Pharmacol Therapeutics. 2016;164:195-203. Doi: 0.1016/j.pharmthera.2016.04.012

7. Waring MJ, Arrowsmith J, Leach AR, Leeson PD, Mandrell S, Owen RM, et al. An analysis of the attrition of drug candidates from four major pharmaceutical companies. Nat Rev Drug Discov. 2015;14(7):475-88. Doi: $10.1038 /$ nrd4609

8. Pushpakom S, lorio F, Eyers P, Escott K, Hopper S, Wells A, et al. Drug repurposing: progress, challenges and recommendations. Nat Rev Drug Discov. 2019;18(1):41-58. Doi: 10.1038/nrd.2018.168

9. Ashburn T, Thor K. Drug Repositioning: Identifying and developing new uses for existing drugs. Nat Rev Drug Discov. 2004;3(8):673-83. Doi: 10.1038/nrd1468

10. Minghetti P, Lanati E, Godfrey J, Solà-Morales O, O. W, S. S. From off-label to repurposed drug in nononcological rare diseases: definition and state of the art in selected EU countries. MA@PoC. 2017;1 (1): e87-e97. Doi: 10.5301/maapoc.0000016

11. Breckenridge A, Jacob R. Overcoming the legal and regulatory barriers to drug repurposing. Nat Rev Drug Discov. 2019;18(1):1-2. Doi: 10.1038/nrd.2018.92

12. Nosengo N. Can you teach old drugs new tricks? Nature. 2016;534(7607):314-6. Doi: 10.1038/534314a

13. Corsello S, Bittker J, Liu Z, Gould J, McCarren P, Hirschman J, et al. The drug repurposing hub: a nextgeneration drug library and information resource. Nat Med. 2017;23(4):405-8. Doi: 10.1038/nm.4306 
14. Cha Y, Erez T, Reynolds I, Kumar D, Ross J, Koytiger G, et al. Drug repurposing from the perspective of pharmaceutical companies. British J Pharmacology. 2018;175(2):168-80. Doi: 10.1111/bph.13798

15. Sleire L, Førde HE, Netland IA, Leiss L, Skeie BS, PØ. E. Drug repurposing in cancer. Pharmacol Res. 2017;124:74-91 Doi: 10.1016/j.phrs.2017.07.013

16. Chen PC, Liu X, Y. L. Drug Repurposing in anticancer reagent development. Comb Chem High Throughput Screen. 2017;20(5):395-402. Doi: 10.2174/1386207319666161226143424

17. Gilbert DC, Vale C, Haire R, Coyle C, Langley RE. Repurposing vitamin D as an anticancer drug. Clin Oncol (R Coll Radiol). 2016;28(1):36-41. Doi: 10.1016/j.clon.2015.10.004

18. Athauda D, Foltynie T. Drug repurposing in Parkinson's disease. CNS drugs. 2018;32(8):747-61. Doi: 10.1007/s40263-018-0548-y

19. Mercorelli B, Palù G, Loregian A. Drug repurposing for viral infectious diseases: how far are we? Trends Microbiol. 2018;26(10):865-76. Doi: 10.1016/j.tim.2018.04.004

20. Konreddy AK, Rani GU, Lee K, Choi Y. Recent drug-repurposing-driven advances in the discovery of novel antibiotics. Curr Med Chem. 2019;26(28):5363-88. Doi: 10.2174/0929867325666180706101404

21. Kruse RL, Vanijcharoenkarn K. Drug repurposing to treat asthma and allergic disorders: progress and prospects. Allergy. 2018;73(2):313-22. Doi: 10.1111/all.13305

22. Sisignano M, Parnham MJ, Geisslinger G. Drug repurposing for the development of novel analgesics. Trends Pharmacological Sci. 2016;37(3):172-83. doi: 10.1016/j.tips.2015.11.006

23. Panchapakesan U, Pollock C. Drug repurposing in kidney disease. Kidney Int. 2018;94(1):40-8. Doi: 10.1016/j.kint.2017.12.026

24. Walton GM, Stockley JA, Griffiths D, Sadhra CS, Purvis T, Sapey E. Repurposing treatments to enhance innate immunity. Can statins improve neutrophil functions and clinical outcomes in COPD? J Clin Med. 2016;5(10):89. Doi: 10.3390/jcm5100089

25. George CH, Mitchell AN, Preece R, Bannister ML, Yousef Z. Pleiotropic mechanisms of action of perhexiline in heart failure. Expert Opin Ther Pat. 2016;26(9):1049-59. Doi: 10.1080/13543776.2016.1211111

26. Korkmaz-Icöz S, Radovits T, Szabó G. Targeting Phosphodiesterase 5 as a Therapeutic Option Against Myocardial Ischaemia/Reperfusion Injury and for Treating Heart Failure. Br J Pharmacol. 2018;175(2):223-31. Doi: 10.1111/bph.13749

27. Fuster V, Chesebro J. Aspirin for primary prevention of coronary disease. Eur Heart J. 1995; Suppl E:16-20. Doi: 10.1093/eurheartj/16.suppl_E.16

28. Barnett CF, Machado RF. Sildenafil in the treatment of pulmonary hypertension. Vasc Health Risk Manag. 2006;2(4):411-22. Doi: 10.2147/vhrm.2006.2.4.411

29. Baker NC, Ekins S, Williams AJ, Tropsha A. A bibliometric review of drug repurposing. Drug Discov Today. 2018;23(3):661-72. Doi: 10.1016/j.drudis.2018.01.018

30. COVID 19 - List Results - ClinicalTrials.gov 2020. Available from: https://clinicaltrials.gov/

31. Schlitzer M. Malaria Chemotherapeutics Part I: History of antimalarial drug development, currently used therapeutics, and drugs in clinical development. ChemMedChem. 2007;2(7):944-86. Doi: 10.1002/ cmdc. 200600240

32. Loeb F, Clark W, Coatney G. Activity of a New Antimalarial Agent, Chloroquine (SN 7618). J Am Med Assoc. 1946;130:1069. Doi: 10.1001/jama.1946.02870160015006 
33. Keyaerts E, Vijgen L, Maes P, Neyts J, Van M. In vitro inhibition of severe acute respiratory syndrome coronavirus by chloroquine. Biochem Biophys Res Commun. 2004;323(1):264-8. Doi: 10.1016/j. bbrc.2004.08.085

34. Gao J, Tian Z, Yang X. Breakthrough: chloroquine phosphate has shown apparent efficacy in treatment of COVID-19 associated pneumonia in clinical studies. Biosci Trends. 2020;14(1):72-3. Doi: 10.5582/ bst.2020.01047

35. Costedoat-Chalumeau N, Dunogué B, Morel N, Guern V, Guettrot-Imbert G. Hydroxychloroquine: a multifaceted treatment in Lupus. Presse Med. 2014;43(6 Pt 2). Doi: 10.1016/j.lpm.2014.03.007

36. PubChem. Hydroxychloroquine compound summary 2020. Available from: https://pubchem.ncbi.nlm.nih. gov/compound/Hydroxychloroquine

37. Hughes G. Hydroxychloroquine: an update. Lupus. 2018;27(9):1402-3. Doi: 10.1177/0961203318787040

38. Yazdany J, Kim A. Use of Hydroxychloroquine and Chloroquine during the COVID-19 pandemic: What Every Clinician Should Know. Ann Intern Med. 2020(3):1-3. Doi: 10.7326/M20-1334

39. Zhou D, Dai S, Tong Q. COVID-19: A Recommendation to examine the effect of hydroxychloroquine in preventing infection and progression. J Antimicrob Chemother. 2020. Doi: 10.1093/jac/dkaa114 [Epub ahead of print]

40. Barbosa J, Kaitis D, Freedman R, Le K, Lin X. Clinical outcomes of hydroxychloroquine in hospitalized patients. Available from: https://www.medrxiv.org/content/10.1101/2020.03.22.20040758v3

41. Gautret P, Lagier J, Parola P, Hoang V, Meddeb L, Mailhe M, et al. Hydroxychloroquine and Azithromycin as a treatment of COVID-19: results of an open-label non-randomized clinical trial. Int J Antimicrob Agents. 2020:105949. doi: 10.1016/j.jiantimicag.2020.105949

42. Cunningham AG, H. Koh, D. Treatment of COVID-19: old tricks for new challenges. Crit Care. 2020;24:91. doi: 10.1186/s13054-020-2818-6

43. Lai C, Shih T, Ko W, Tang H, Hsueh P. severe acute respiratory syndrome coronavirus 2 (SARS-CoV-2) and Coronavirus disease-2019 (COVID-19): the epidemic and the challenges. Int J Antimicrob Agents. 2020;55(3):105924. doi: 10.1016/j.ijantimicag.2020.105924

44. Liu Y, Li J, Feng Y. Critical care response to a hospital outbreak of the 2019-nCoV infection in Shenzhen, China. Crit Care. 2020;24(1):56. doi: 10.1186/s13054-020-2786-X

45. Grein J, Ohmagari N, Shin D, Diaz G, Asperges E, Castagna A, et al. Compassionate use of remdesivir for patients with severe Covid-19. N Engl J Med. 2020. doi: 10.1056/NEJMoa2007016

46. Sui J, Li W, Roberts A, Matthews LJ, Murakami A, Vogel L, et al. Evaluation of human monoclonal antibody 80R for immunoprophylaxis of severe acute respiratory syndrome by an animal study, epitope mapping, and analysis of spike variants. J Virol. 2005;79(10):5900-6. doi: 10.1128/JVI.79.10.5900-5906.2005

47. Both L, Banyard AC, van Dolleweerd C, Wright E, Ma JKC, Fooks AR. Monoclonal antibodies for prophylactic and therapeutic use against viral infections. Vaccine. 2013;31(12):1553-9. doi: 10.1016/j. vaccine.2013.01.025

48. Masters PS. The molecular biology of coronaviruses. Adv Virus Res. 2006;66:193-292. doi: 10.1016/S00653527(06)66005-3

49. Shanmugaraj B, Siriwattananon K, Wangkanont K, Phoolcharoen W. Perspectives on monoclonal antibody therapy as potential therapeutic intervention for coronavirus disease-19 (COVID-19). Asian Pac J Allergy Immunol. 2020;38(1):10-8. Doi: 10.12932/AP-200220-0773. 
50. Jafarzadeh A, Nemati M, Khorramdelazad H, Hassan ZM. Immunomodulatory properties of cimetidine: Its therapeutic potentials for treatment of immune-related diseases. Int Immunopharmacol. 2019;70:156-166. doi:10.1016/j.intimp.2019.02.026

51. Rogosnitzky, M., Berkowitz, E., \& Jadad, A. R. Delivering Benefits at Speed through Real-World Repurposing of Off-Patent Drugs: The COVID-19 Pandemic as a Case in Point. JMIR Public Health Surveill. 2020. Doi: 10.2196/1999 [Epub ahead of print]

52. Borrel B. New York clinical trial quietly tests heartburn remedy against coronavirus. Science; 2020. Available from: https://www.sciencemag.org/news/2020/04/new-york-clinical-trial-quietly-tests-heartburn-remedy-againstcoronavirus

53. Zhou Y, Qin Y, Lu Y, Sun F, Yang S, Harypursat V, et al. Effectiveness of glucocorticoid therapy in patients with severe novel coronavirus pneumonia: protocol of a randomized controlled trial. Chin Med J. 2020. Doi: 10.1097/CM9.0000000000000791 [Epub ahead of print]

54. Thalidomide combined with low-dose glucocorticoid in the treatment of COVID-19 Pneumonia. Available from: https://www.preprints.org/manuscript/202002.0395/v1

55. Deftereos S, Siasos G, Giannopoulos G, Vrachatis D, Angelidis C, Giotaki S, et al. The greek study in the effects of colchicine in COVID-19 complications prevention (GRECCO-19 Study): rationale and study design. Hellenic J Cardiol. 2020. doi: 10.1016/j.hjc.2020.03.002 [Epub ahead of print]

56. Kupferschmidt K, Cohen J. Race to find COVID-19 treatments accelerates. Science. 2020;367(6485):14123. Doi: $10.1126 /$ science.367.6485.1412

57. Rosa S, Santos W. Clinical trials on drug repositioning of COVID-19. Rev Panam Salud Publica. 2020;44:e40 Doi: 10.26633/RPSP.2020.40

58. Wilson M, Fleming K, Kut iM, Looi L, Lag oN, Ru K. Access to pathology and laboratory medicine services: a crucial gap. Lancet. 2018;391(10133):1927-38. Doi: 10.1016/S0140-6736(18)30458-6

59. COVID-19: what science advisers must do now. Nature Publishing Group; 2020 [updated 2020-03-18. Available from: https://media.nature.com/original/magazine-assets/d41586-020-00772-4/d41586-020-00772-4.pdf

60. Abdullah N, Abril M, Amare A, Amuasi J, Auewarakul P, Augier A,et al. Global Coalition to Accelerate COVID-19 Clinical research in resource-limited settings. Lancet. 2020;395(10233):1322-1325. Doi: 10.1016/ S0140-6736(20)30798-4

61. Fact sheet for health care providers emergency use authorization (EUA) of hydroxychloroquine sulfate supplied from the strategic national stockpile for treatment of Covid-19 in certain hospitalized patients, (2020). Available from: https://www.fda.gov/media/136535/

62. Charles H, Evans J, Suzanne T. Statistical approaches to analysis of small clinical trials: National Academies Press (US); 2001. Available from: https://www.nap.edu/read/10078/chapter/5

63. Brody T. Clinical Trials - 2nd Edition: Elsevier; 2016. Available from: https://www.elsevier.com/books/clinicaltrials/brody/978-0-12-804217-5.

64. Mills A, Durepos G, Wiebe E. Event-driven research. In: Encyclopedia of Case Study Research. SAGE; 2010. Available from: https://methods.sagepub.com/reference/encyc-of-case-study-research/n133.xml. doi: $10.4135 / 9781412957397$

65. Leng Z, Zhu R, Hou W, Feng Y, Yang Y, Han Q, et al. Transplantation of ACE2 - mesenchymal stem cells improves the outcome of patients with COVID-19 pneumonia. Aging Dis. 2020;11(2):216-28. Doi: 10.14336/ AD.2020.0228 
66. ClinicalTrial.gov. Hydroxychloroquine versus placebo in COVID-19 patients at risk for severe disease. University Hospital, Angers; 2020. Available from: https://clinicaltrials.gov/ct2/show/NCT04325893.

67. ClinicalTrial.gov. Evaluation of the efficacy and safety of sarilumab in hospitalized patients with COVID-19. Regeneron Pharmaceuticals; 2020 . Available from: https://clinicaltrials.gov/ct2/show/NCT04315298.

68. Zimmer C. Scientists identify 69 drugs to test against the Coronavirus. New York Times. 202020200322. Available from: https://www.nytimes.com/2020/03/22/science/coronavirus-drugs-chloroquine.html 